\title{
WIZERUNEK I WSKAŹNIKOWOŚĆ UKŁADÓW CIAŁA LUDZKIEGO W REKLAMIE NA PRZYKŁADZIE POLSKIEJ PRASY KOBIECEJ - BADANIE I UWAGI WSTĘPNE
}

\author{
KINGA KOWALEWSKA \\ JOANNA PUPPEL
}

\section{Wstęp}

Wizerunek stanowi nieodłączną część wszelkiej ziemskiej cielesności (bytowości fizycznej) (za S. Puppel, 2016: 109). Ta cielesność/ fizyczność jest wyposażona $\mathrm{w}$ atrybuty nadawczo-odbiorcze i tym samym podlega polityce wizerunku, który zarządza „wyglądem-oglądem”. Tym bardziej wizerunek człowieka w reklamie podlega prawu „wyglądu-oglądu” ponieważ jest nieustannie przez swoją statyczność, poddawana procesom przekazu, tj. nadawania i odbioru. Reklama natomiast może być najogólniej zdefiniowana jako „zjawisko o charakterze ekonomicznym, o silnym nacechowaniu emocjonalnym w celu osiągnięcia sukcesu perswazyjnego" (Kowalewska, 2013: 181).

Podążając tropem wizerunkowości, Strzelecki, et al., (2007) podają, iż wizerunek to subiektywne wyobrażenie, jakie mamy o danej osobie, obraz powstały przez fragmentaryczne i przypadkowe uchwycenie poszczególnych cech i szczegółów wyglądu zewnętrznego i zachowania wynikające $\mathrm{z}$ relacji $\mathrm{w}$ jakiej $\mathrm{z}$ daną osobą pozostajemy. Wizerunek to twór wielowarstwowy, dynamiczny i wciąż ulegający przeobrażeniom. Aby był przekonywujący musi być kompletny, spójny i prawdziwy. Jednym słowem człowiek zanurzony jest w niezwykle istotnym wymiarze „kul- 
tury wizualnej” (zob. Ball, 2003; Mirzoeff, 1998) i wszystkie „fragmentaryczne i przypadkowe cechy i szczegóły wyglądu zewnętrznego" (Strzelecki, et al., 2007: 174) służą od niepamiętnych czasów jako główny wskaźnik cielesności ludzkiej.

Każdej cesze ludzkiego ciała przypisywano i przypisuje się określoną semantyczną wskaźnikowość, także związaną z nią określoną wartość komunikacyjno-mediacyjną (J. Puppel, 2016). Wskaźnikowość definiujemy tutaj jako bezpośrednią korelację czasowo-przestrzenną (typu 'tu i teraz') istniejącą pomiędzy widzialnym określonym układem ciała a jego znaczeniem. I tak, w niniejszym opracowaniu chcemy przyjrzeć się trzem układom ciała ludzkiego na przykładzie przeanalizowanych przez nas reklam prasowych zamieszczonych w czasopismach i magazynach skierowanych do kobiet. Zakładamy bowiem, iż:

1. W układzie twarzy - twarz wzmacnia przekaz reklamowy,

2. W układzie twarz-ręka - ręka wzmacnia twarz, przez co wzmacnia przekaz reklamowy,

3. W układzie przód postaci - twarz wzmacnia całą fasadę człowieka (S. Puppel, 2016), przez co wzmacnia przekaz w reklamie.

1a. 'Układ twarzy' jest najważniejszym w kulturze wizualnej elementem 'komunikacji wskaźnikowej’ (ang. indexical communication). Jest nie tylko jednym z najważniejszych wskaźników komunikacji, ale również 'estetycznej' obecności w otwartej przestrzeni publicznej, do której niewątpliwie należy przekaz reklamowy (Shohat i Stam, 1998). Twarz możemy opisać jako układ części anatomicznych, których wzajemny stosunek i współdziałanie nadaje jej odpowiedni wyraz jednak nas interesuje twarz jako obszar komunikologii skupiającej się na badaniu wszelkich przejawów komunikacji międzyludzkiej (wszelkie interakcje społeczne ale również wyrażanie emocji). Tym samym twarz jest centralnym elementem ludzkiego potencjału komunikacyjno-mediacyjnego realizowanego w nieskończonej liczbie wydarzeń komunikacyjnych (zob. J. Puppel, 2011; 2016).

2a. 'Układ twarz-ręka' w swojej 'zmiksowanej/zblendowanej' naturze jest najsilniejszym układem należącym do ludzkiej topografii performatywności (Goffman, 1969). W 'cyklu dziennym' układ ten jest najbardziej ekspresyjną częścią ludzkiej performatywności o najwyższym indeksie performatywności (zob. J. Puppel, 2013).

3a. 'Układ przód postaci' ściśle koreluje ze zjawiskiem frontalnego przedstawienia ciała ludzkiego w procesie komunikacji zarówno werbalnej jak i niewerbalnej. Układ przodu ciała jest nierozerwalnie związany z pojęciem „postaciowości”, czyli z działalnością wizerunkową człowieka. 'Układ przodu postaci', czyli fasada jest niezwykle istotna w budowaniu wizerunku danej jednostki i tym samym skuteczności tej wizerunkowości (zob. S. Puppel, 2016). Zakładamy również, za S. Puppel (2016), że przód postaci jest tym elementem układu ciała ludzkiego, który najczęściej jest wykorzystywany do wyrażania cielesności w otwartej przestrzeni publicznej. 


\section{Badanie}

Przedmiotem badania jest określony układ ciała wraz z przypisaną mu wartością komunikacyjno-mediacyjną, który występuje w warstwie wizualnej w reklamach prasowych.

\subsection{Cel badania}

Celem niniejszego badania i krótkiego opracowania jest zwrócenie uwagi i przeanalizowanie trzech ważnych układów ciała ludzkiego w świetle wybranych reklam prasowych. Szczegółowym celem badania jest zidentyfikowanie tych układów, które najbardziej wzmacniają przekaz w prasowych komunikatach reklamowych.

\subsection{Założenia}

Zakłada się, że każda cecha zewnętrznej cielesności, a także każdy element ciała niosą ze sobą określoną semantyczną wskaźnikowość oraz, że ich układy mają właściwość wzmacniającą tę wskaźnikowość.

\subsection{Hipotezy szczegółowe}

W badaniu postawiono następujące hipotezy:

H1: Twarz wzmacnia przekaz reklamowy ('układ twarzy').

H2: Ręka wzmacnia twarz ('układ twarz-ręka'), przez co wzmacnia przekaz reklamowy.

H3: Twarz wzmacnia fasadę człowieka ('układ przód postaci'), przez co wzmacnia przekaz w reklamie.

\subsection{Metoda badania}

Podstawą badania jest metoda analizy ilościowej. Pozwala ona na zidentyfikowanie najczęściej stosowanych układów wzmacniających przekaz $\mathrm{w}$ prasowych komunikatach reklamowych.

\subsection{Materiał badawczy}

Korpus badawczy oparty został o reklamy prasowe z różnorodnej polskiej prasy kobiecej z lat 2015-2016. Materiał całościowy obejmował wszystkie przekazy reklamowe pochodzące $\mathrm{z}$ następujących czasopism oraz magazynów skierowanych głównie do kobiet: Wysokie Obcasy 5/2016; Pani 5/2016, 11/2016; Zwierciadto 
5/2016, 10/2016; Uroda Życia 09/2015, 10/2016; Twój Styl 09/2015, 12/2015, 02/2016, 09/2016; Grazia 10/2016; Gala 25/04/2016; Viva 21/04/2016; Świat Kobiety 06/2016, 07/2016, 08/2016; Party 25/04/2016; Kobieta i Życie 8/2016, 9/2016, 10/2016; Pani Domu 01-15/08/2016; Tina 20.07.2016.

\subsection{Interpretacja danych}

$\mathrm{Na}$ podstawie zebranego materiału badawczego dokładaną analizą objęto 824 reklamy prasowe z 23 pozycji prasowych. Spośród wszystkich reklam wyodrębniono te, których przekaz wizualny przedstawiał wizerunek postaci ludzkiej w całości lub fragmentarycznie. W analizowanym materiale wstępnym składającym się z 824 reklam, 203 reklamy sklasyfikowano jako reklamy nie ukazujące postaci ludzkiej (zob. Zdjęcie nr 1), natomiast 621 jako przedstawiające wizerunek postaci ludzkiej (zob. Tabela nr 1).

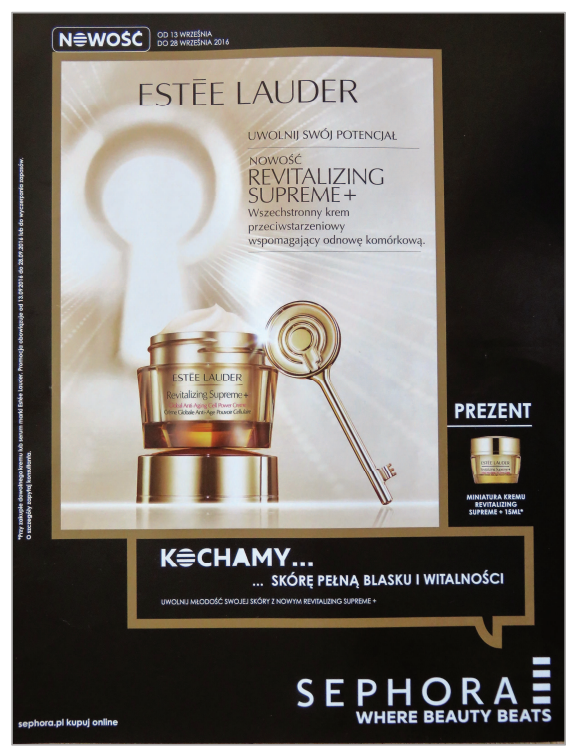

Zdjęcie nr 1. Reklama prasowa nie ukazująca postaci ludzkiej

Tabela nr 1. Kategorie oraz ich reprezentacje liczbowe w pierwotnym materiale badania

\begin{tabular}{|c|l|c|c|}
\hline Lp. & \multicolumn{1}{|c|}{ Kategoria } & Wartość liczbowa & $\begin{array}{c}\text { Wartość procentowa } \\
{[\%]}\end{array}$ \\
\hline 1. & Korpus & 824 & 100 \\
\hline 2. & Reklama bez postaci ludzkiej & 203 & 24,6 \\
\hline 3. & Reklama z wizerunkiem postaci ludzkiej & 621 & 75,4 \\
\hline
\end{tabular}




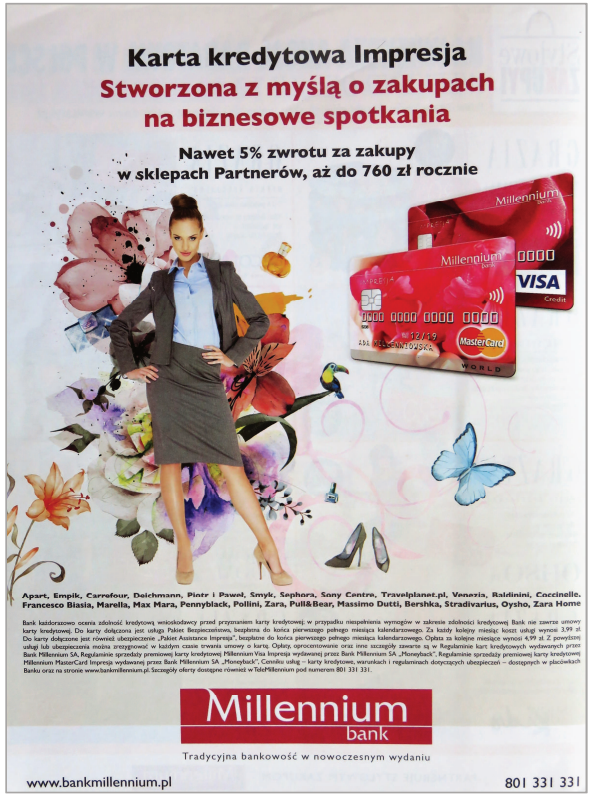

Zdjęcie nr 2. Reklama prasowa ukazująca przód ciała/całą postać

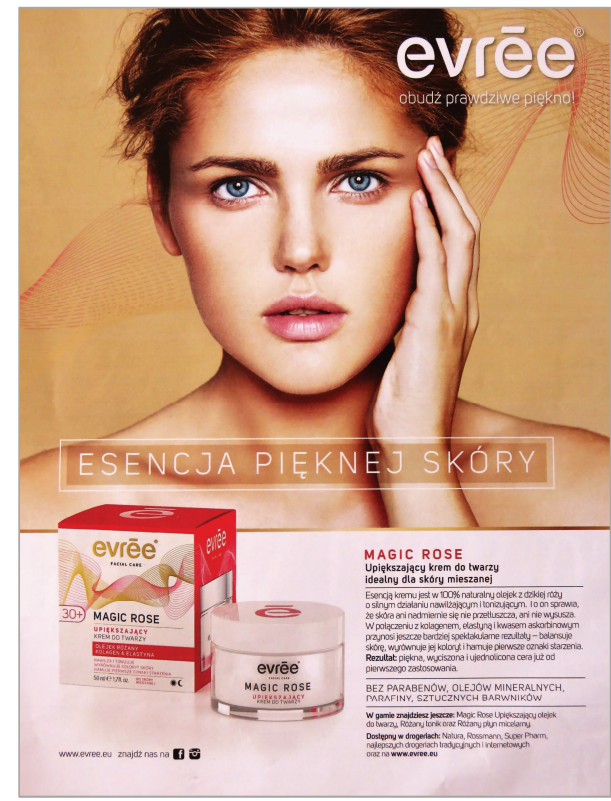

Zdjęcie nr 4. Reklama prasowa ukazująca twarz wraz z ręką

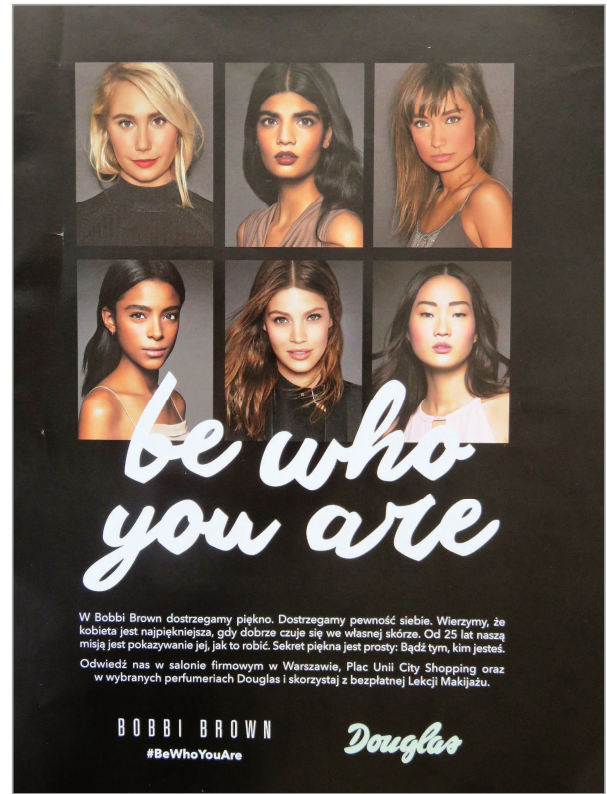

Zdjęcie nr 3. Reklama prasowa ukazująca twarz

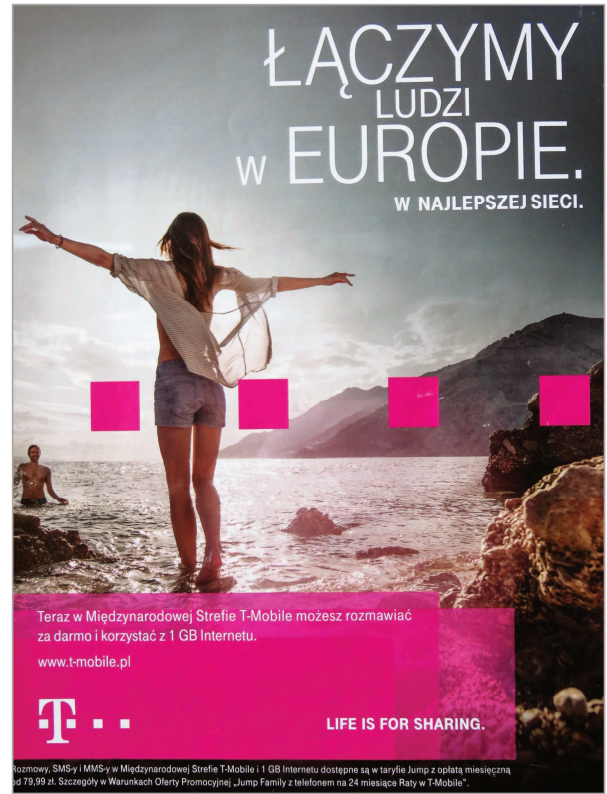

Zdjęcie nr 5. Reklama prasowa ukazująca tył ciała 
W drugim etapie interpretacji danych liczbę 621 reklam z wizerunkiem postaci ludzkiej uznano za $100 \%$ materiału docelowego. Wprowadzono kategoryzację pod względem ukazanej części (całość lub układ) oraz strony ciała ludzkiego (przód lub tył). Pod uwagę zostały wzięte następujące kategorie: ,przód ciała/cała postać” (zob. Zdjęcie nr 2), „twarz” (zob. Zdjęcie nr 3), „twarz + rękę” (zob. Zdjęcie nr 4), „tył ciała” (zob. Zdjęcie nr 5), ,inne” (zob. Zdjęcie nr 6). Kategoria ,inne” obejmuje reklamy przedstawiające wyizolowane części ciała np. stopę, brzuch, pośladki i inne poszczególne części oprócz twarzy (zob. Tabela nr 2). Należy także dodać, że w kategorii „przód ciała/cała postać” zawiera się pośrednio kategoria „twarz”.

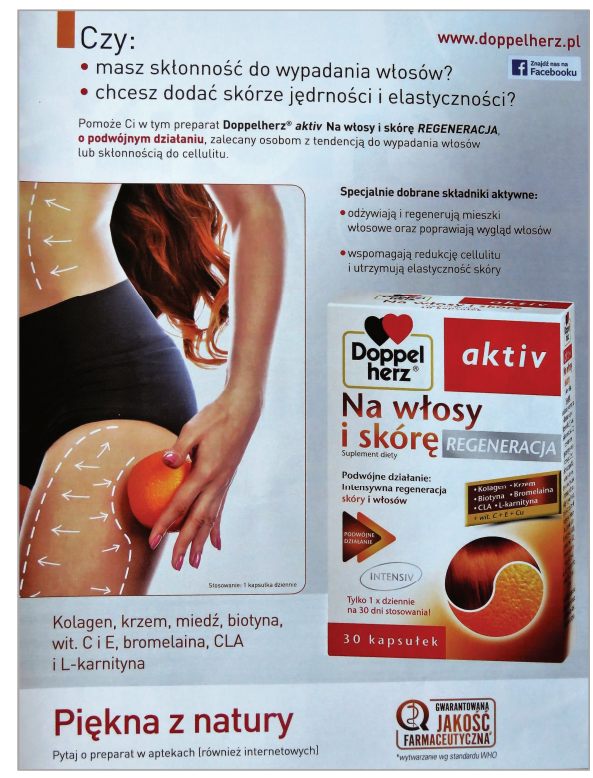

Zdjęcie nr 6. Reklama prasowa ukazująca inne części ciała

Poniżej tabela przedstawiająca wyniki badań w postaci liczbowej oraz procentowej.

Tabela nr 2. Kategorie oraz ich reprezentacje liczbowe w docelowym materiale badania

\begin{tabular}{|c|l|c|c|}
\hline Lp. & \multicolumn{1}{|c|}{ Reklama prezentująca } & Wartość liczbowa & $\begin{array}{c}\text { Wartość procentowa } \\
{[\%]}\end{array}$ \\
\hline 1. & Postać ludzką & 621 & 100 \\
\hline 2. & Przód ciała/całą postać & 220 & 35,4 \\
\hline 3. & Twarz & 139 & 22,5 \\
\hline 4. & Twarz+rękę & 193 & 31,0 \\
\hline 5. & Tył ciała & 16 & 2,6 \\
\hline 6. & Inne & 53 & 8,5 \\
\hline
\end{tabular}




\subsection{Wyniki}

Wyniki badania wskazują jednoznacznie, że najliczniej reprezentowana jest kategoria „przód ciała” - 35,5\%, która obejmuje fasadę człowieka i zawiera w sobie element „twarz” (zob. Wykres nr 1). Kolejnym układem wzmacniającym przekaz jest „twarz + ręka” - 31,0\%, a następnie sama „twarz” - 22,5\%. Kategoria „tył ciała" obejmuje 2,6\% badanego materiału, natomiast pozostałe fragmentaryczne prezentacje ludzkiego ciała stanowią $8,5 \%$. Łącznie twarz występuje w $88,9 \%$ przeanalizowanych reklam ukazujących ciało człowieka.

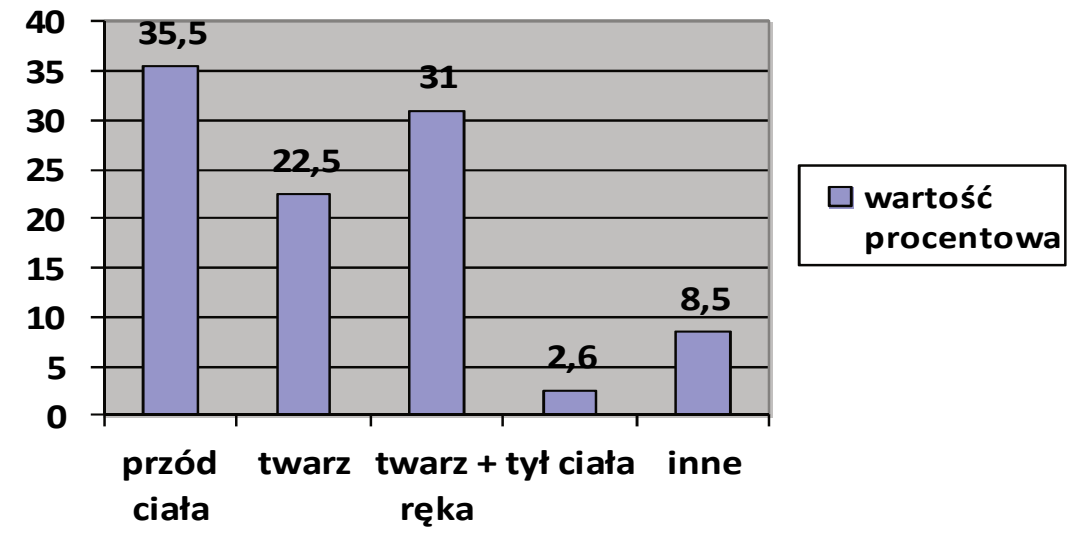

Wykres nr 1. Wartość procentowa występowania poszczególnych układów ciała ludzkiego

\subsection{Dyskusja}

Analiza ilościowa danych pozwoliła na zidentyfikowanie najczęściej używanego układu w obrębie ciała i jego poszczególnych części, któremu przypisuje się najwyższy wskaźnik semantyczny. Z badania wynika, że największą wartość komunikacyjno-mediacyjną mają te układy, które zawierają twarz.

Fasada ciała w sposób biologiczny zawiera ten właśnie element i stanowi zatem najbardziej naturalny układ komunikacyjny (ponad 1/3 analizowanych przypadków). Okazuje się, że z punktu widzenia wzmacniania przekazu, to właśnie twarz, nawet w izolacji w stosunku do pozostałych części ludzkiego ciała, ma wysoki wskaźnik semantyczny (ponad 1/5 przypadków). Wzmocnienie wskaźnika semantycznego twarzy następuje w momencie, gdy występuje ona w diadycznym 'układzie twarz + ręka' (prawie $1 / 3$ przypadków). 


\section{Wnioski i uwagi}

1. Analiza ilościowa materiału badawczego pozwala na określenie hipotez jako trafnie postawionych i wskazuje, że w warstwie wizualnej prasowych komunikatów reklamowych 'układ twarzy' wzmacnia przekaz reklamowy. W 'układzie twarz-ręka' ręka wzmacnia twarz, przez co wzmacnia przekaz reklamowy i w 'układzie przód postaci' twarz wzmacnia fasadę, przez co wzmacnia przekaz reklamowy.

2. Mimo, iż w naturalnym środowisku obserwujemy osoby zarówno z przodu, z tyłu, jak i z boku, w reklamie ukazuje się postać ludzką w najbardziej komfortowej pozycji z punktu widzenia komunikacji międzyludzkiej, czyli z przodu, a więc fasadowo.

3. Prawie wszystkie osoby na zdjęciach reklamowych patrzą prosto w obiektyw stwarzając wrażenie kontaktu wzrokowego - tym samym spełniając podstawowy warunek komunikacji międzyludzkiej, czyli 'twarzą-w-twarz'.

4. Bardzo rzadko występuje w badanych reklamach fragmentaryzacja twarzy znacznie częściej fragmentarycznie ukazuje się inne części ciała - np. nogi czy stopy.

5. Po analizie całościowego materiału badawczego można zauważyć silny antropocentryzm w warstwie wizualnej reklam prasowych - ponad $75 \%$ procent reklam przedstawia postać ludzką - w całości lub fragmentarycznie.

\section{Bibliografia}

Bal, M. 2003. „Visual essentialism and the object of visual culture”. Journal of Visual Culture 2. 5-32. Goffman, E. 1969. The presentation of self in everyday life. London: Allen Lane The Penguin Press.

Kowalewska, K. 2013. „Sytuacja komunikacyjna między nadawcą a odbiorcą treści reklamowych”. W zbiorze: Puppel, S. i T. Tomaszkiewicz (red.). Scripta manent - res novae. Poznań: Wydawnictwo Naukowe UAM. 181-193.

Mirzoeff, N. (red.). 1998. The visual culture reader. London: Routledge.

Puppel, J. 2011. „Uwagi w sprawie zarządzania twarzą w przestrzeni publicznej”. W zbiorze: Puppel, S. (red.). Transkomunikacja. Scripta de Communicatione Posnaniensi. Poznań: Zakład Graficzny UAM. 81-89.

Puppel, J. 2013. „Facework and gestures: a preliminary analysis of the communicative power of human performative non-verbal practices". Scripta Neophilologica Posnaniensia XIII. 85-90.

Puppel. J. 2016. „Wskaźnikowość twarzy ludzkiej: krótki przegląd problematyki”. Scripta Neophilologica Posnaniensia XVI. 201-206.

Puppel, S. 2016. „Kuźnia Hefajstosa czyli krótki zarys teorii wizerunku w komunikacji człowieka”. Scripta Neophilologica Posnanienisia XVI. 109-124.

Sadowski, P. 2009. From interaction to symbol: a systems view of the evolution of signs and communication. Amsterdam: John Benjamins.

Shohat, E. i R. Stam. 1998. „Narrativizing visual culture: towards a polycentric aesthetics”. W zbiorze: Mirzoeff, N. (red.). The visual culture reader. London: Routledge. 27-49.

Strzałko, J., Kaszycka, K. i B. Kujawa. 1996. „Najpiękniejsza jest przeciętna”. Wiedza i Życie 5. 20-22.

Strzelecki, W., Cybulski, M., Strzelecka, M. i A. Dolczewska-Samela. 2007. „Zmiana wizerunku medialnego kobiety a zaburzenia odżywiania we współczesnym świecie”. Nowiny Lekarskie 76. 173-181. 